Der nachschaffende Hörer 


\section{Ulrike Kranefeld}

\section{Der \\ nachschaffende Hörer}

Rezeptionsästhetische Studien zur Musik Robert Schumanns

Verlag J. B. Metzler Stuttgart · Weimar 
Die Deutsche Bibliothek - CIP-Einheitsaufnahme

Kranefeld, Ulrike:

Der nachschaffende Hörer / Rezeptionsästhetische Studien zur Musik

Robert Schumanns / Ulrike Kranefeld.

- Stuttgart ; Weimar : Metzler, 2000

ISBN 978-3-476-45256-6

ISBN 978-3-476-02750-4 (eBook)

DOI 10.1007/978-3-476-02750-4

Dieses Werk einschließlich aller seiner Teile ist urheberrechtlich geschützt. Jede Verwertung außerhalb der engen Grenzen des Urheberrechtsgesetzes ist ohne Zustimmung des Verlages unzulässig und strafbar. Das gilt insbesondere für Vervielfältigungen, Übersetzungen, Mikroverfilmungen und die Einspeicherung und Verarbeitung in elektronischen Systemen.

M \& P Schriftenreihe für Wissenschaft und Forschung

(C) 2000 Springer-Verlag GmbH Deutschland

Ursprünglich erschienen bei J.B.Metzlersche Verlagsbuchhandlung und Carl Ernst Poeschel Verlag GmbH in Stuttgart 2000 
"Es verhält sich mit der Aufgabe der Aesthetik nicht viel besser, als mit der Quadratur des Zirkels. Zwischen Theorie und Praxis, Regel und Beispiel, Gesetz und Freiheit bleibt immer ein unendlicher Bruch uebrig und vielleicht ist eben dieser Bruch mehr werth, als das Ganze. Das Schöne wäre vielleicht nicht mehr schön, wenn irgend ein Denker das Geheimnis enträthselte."

Robert Schumanns Abschrift eines Ausschnitts aus Wolfgang Menzels Artikel Ästhetik im Literatur-Blatt (MS VI, E 20) 


\section{Danksagung}

Mein besonderer Dank gilt meinem Betreuer und Doktorvater Prof. Dr. Martin Geck (Universität Dortmund) für viele wertvolle Anregungen während der Entstehung dieser Studien. Fruchtbare künstlerische Impulse sowohl im Hinblick auf die Klaviermusik Robert Schumanns als auch auf weit darüber hinausgehende ästhetische Fragen verdanke ich meinem musikalischen Lehrer Prof. Gregor Weichert (Musikhochschule Detmold, Abteilung Münster). Vielen Dank zudem an Prof. Dr. Eva-Maria Houben und Dr. Ulrich Tadday für eine Vielzahl hilfreicher Hinweise. Dank schulde ich außerdem Beate Frey, Willi Hagemann, Benno Hammerschmidt und Frank Schasse für ihre nimmermüden Korrekturarbeiten in der Endphase der Fertigstellung dieser Arbeit. Nicht zuletzt herzlichen Dank an meine Eltern, die mir meine umfassende künstlerische und wissenschaftliche Ausbildung ermöglicht haben. Die vorliegende Arbeit wurde durch ein Graduiertenstipendium des Landes Nordrhein-Westfalen gefördert und ist vom Promotionsausschuß des Fachbereichs 16 der Universität Dortmund als Dissertationsschrift angenommen worden. 


\section{Inhaltsverzeichnis}

Einleitung

I Musik in der zurückspiegelnden Phantasie 6

1. Momente der zurückspiegelnden Phantasie 6

1.1. Das gesamtkünstlerisch-schöpferische Moment 8

1.2. Das synthetisierende Moment 13

1.3. Das mehrperspektivische Moment 15

1.4. Individueller Erfahrungshorizont $\quad 18$

1.5. Äußere Bedingungen 24

2. Zurückspiegelnde Phantasie und appellative Struktur des Kunstwerks

II Musik auf dem Papier $\quad 38$

$\begin{array}{ll}\text { 1. Musiklesen } & 38\end{array}$

2. Heterogenität der Zeichen: Schriftsprache und Notenschrift 39

3. Das Robert-Schumann-Kontinuum 45

4. Zwischen Ornament und Hieroglyphe: Arabeske op. 18

4.1. "Zauberisches Genießen" der Musik auf dem Papier 56

4.2. Arabeske: Titel und Erwartungshorizont 61

4.3. Was ist musikalisch ornamental? 62

4.4. "Variationen, aber über kein Thema":

Wiederholungsstrukturen und kompositorisches Konzept $\quad 64$

4.5. Rahmung und Innenbild 71

4.6. Zwischen Ornament und Hieroglyphe 74 
VIII

5. Innere Stimme 77

6. Musik "wie aus der Ferne" 82

6.1. Musikalisch- sprachliche Intertextualität als Appellstruktur für Eingeweihte $\quad 82$

6.2. Ferne als räumliche Dimension 89

6.3. Ferne als zeitliche Dimension 93

6.4. Ferne als romantischer Topos 97

7. Musik auf dem Papier und Werkkonzept 101

III Musik als Klangkörper

1. "Das Verlassen der gewöhnlichen Gesetze der Sinnesvorgänge" Rezeptionsmomente in Malerei und Musik

1.1. Einleitung

1.2. "Schwebend stehen und stehend schweben"

Zum kompositorischen Prinzip des doppelten Rahmens

bei Raphael und Schumann

1.3. "Das Verlassen der perspektivischen Gesetze"

Horizontschichtung bei Raphael und Schumann

1.4. "Das Hinwegschwinden der Symmetrie"

System und Systemlosigkeit als Rezeptionsphänomen

bei Raphael und Schumann

1.5. "Die bildlichen Beschauer des Bildes"

Musikalische und bildnerische Übergangszeichen 
2. "Schwindel der Seele"

Rezeptionsmomente in Dichtung und Musik 140

2.1. Brüche und rascher Wechsel bei Jean Paul und Schumann 140

$\begin{array}{ll}\text { 2.1.1. Bruch } & 141\end{array}$

2.1.2. Rascher Wechsel 148

2.2. "Verwirtte Phantasie" als Rezeptionsphänomen bei

Jean Paul, Shakespeare/Tieck und Schumann 151

2.2.1. "Das Darlehn unserer Ansicht"

Humoristische Sinnlichkeit bei Jean Paul 151

2.2.2. "Getäuschte Phantasie"

Zerstreute Aufmerksamkeit bei Shakespeare/Tieck 154

2.3. Faden und Fäden: Zu einer ästhetischen Kategorie 160

3. Zwischen "Träumerei" und "Traumes Wirren"

Traum, Kunstrezeption und Opiumvergiftung

IV Zusammenfassung

V Abbildungsverzeichnis

181

VI Literaturverzeichnis 


\section{Zur Zitierweise}

\section{Zur Vereinfachung werden im folgenden bei dem Hinweis auf häufig zitierte Literatur Abkürzungen verwendet:}

GS I-IV Robert Schumann: Gesammelte Schriften über Musik und Musiker, 4 Bände, Leipzig 1854, Reprint in 2 Bänden mit einem Nachwort von Gerd Nauhaus, Wiesbaden 1985.

KR I, II Robert Schumann: Gesammelte Scbriften über Musik und Musiker, hrsg. von Martin Kreisig, 5. Aufl., mit den durchgesehenen Nachträgen und Erläuterungen zur 4. Auflage und weiteren, 2 Bände, Leipzig 1914.

JB Jugendbriefe von Robert Scbumann, nach den Originalen mitgetheilt von Clam Schumann, Leipzig 1885.

BW I/I Clara und Robert Schumann. Briefwecbsel. Kritische Gesamtausgabe, hrsg. von Eva Weissweiler, 3 Bde., Bd. I: 1832-1838, Basel und Frankfurt a. M. 1984, Bd. II: 1839, Basel und Frankfurt a. M. 1987.

BNF Robert Scbumanns Briefe. Neue Folge, hrsg. von Friedrich Gustav Jansen, 2. verm. und verb. Auflage, Leipzig 1904.

MS Leander Hotaki: Robert Scbumanns Mottosammlung. Übertragung, Kommentar, Einfiibrung, Freiburg i. Br. 1998. In der jeweiligen Literaturangabe bezeichnet die römische Ziffer die Nummer des Heftes, das E mit arabischer Ziffer die entsprechende Nummer des Notats und die dazugehörige Anmerkung. 
KA Kritische Friedricb-Schlegel-Ausgabe, hrsg. von Ernst Behler, München 1958 ff.

TB 1-III Robert Schumann: Tagebücher, Bd. I: 1827-1838, hrsg. von Georg Eismann, Leipzig 1971, Basel und Frankfurt a. M. o. J., Bd. II: 1836-1854, hrsg. von Gerd Nauhaus, Leipzig 1987, Basel und Frankfurt a. M. o. J., Bd. III: Haushaltsbücher, hrsg. von Gerd Nauhaus, 2 Teile, Teil 1: 1837-1847, Teil 2: 1847-1856, Leipzig 1982, Basel und Frankfurt a. M. o. J.

NZfM Neue Zeitschrift für Musik, Leipzig 1834 ff.

JP Jean Paul: Sämtlicbe Werke, hrsg. von Norbert Miller, München 1959 ff. 